\title{
THE PROPAGATION OF THE WAVES IN THE CTO S.A. TOWING TANK
}

\author{
Marcin Drzewiecki \\ CTO S.A. Ship Design and Research Centre, Poland \\ Gdańsk University of Technology, Poland
}

\begin{abstract}
The paper presents the results of research focused on the wave propagation in the CTO S.A. deepwater towing tank. In the scope of paper, the wavemaker transfer function was determined for regular waves, based on the Biésel Transfer Function and further for irregular waves, based on Hasselman model of nonlinear energy transfer. The phenomena: wave damping, wave breakdown and wave reflection, were measured, analyzed and mathematically modeled. Developed mathematical models allow to calculate the impact of mentioned phenomena on the wave propagation and furthermore to calculate the wave characteristics along the whole measurement area in the CTO S.A. deepwater towing tank, based on wavemaker flap motion control.
\end{abstract}

Keywords: waves, propagation, nonlinear transfer function, towing tank

\section{INTRODUCTION}

During the hydromechanical tests with a model of the object in a sea wave, such as the tests carried out in the CTO S.A. deepwater towing tank (Fig. 1), it is crucial to obtain the spectrum of the generated wave consistent with the modeled sea wave in a reduced scale. The wave should be properly modeled along whole measurement area. The transfer function of the wavemaker and moreover the damping, breakdown and reflection phenomena, have impact on modeling the marine environment conditions.

The knowledge of the above factors is important for realization of the model tests. In the scope of this paper, mentioned factors have been analyzed. The analysis was carried out on the basis of measurements made in CTO S.A.

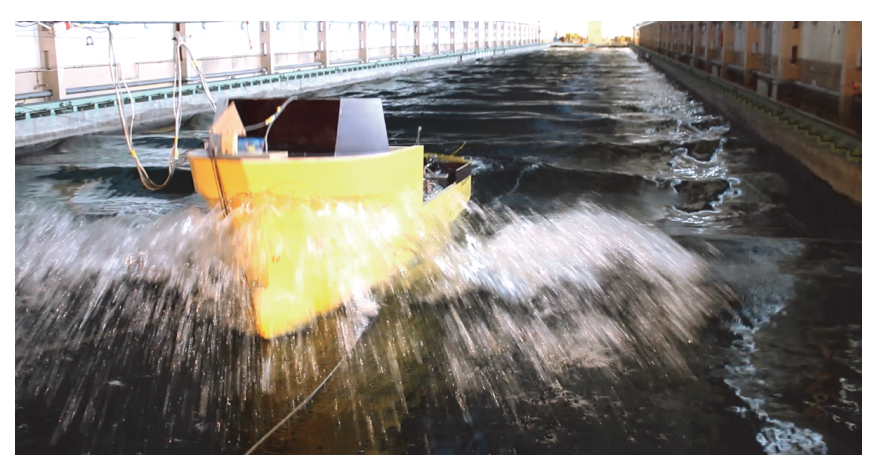

Fig. 1. The seakeeping tests in the CTO S.A. deepwater towing tank. 


\section{TOWING TANK}

The CTO S.A. deepwater towing tank is a research object with $270 \mathrm{~m}$ length, $12 \mathrm{~m}$ width and $6 \mathrm{~m}$ depth, as shown in Fig. 2. Investigations carried out in the towing tank consist in testing the properties of objects floating freely (vessels), anchored (oil rigs) or permanently fixed to the bottom (offshore wind turbines). The tests are conducted for models of objects in a reduced scale. The models are tested in the uniform flow (simulated by motion of the carriage at constant speed) or subjected to the impact of the waves for modeling the impact of the marine environment.

\section{WAVEMAKER}

The waves corresponding to ocean waves in a reduced scale are generated by the rigid flap wavemaker with single articulation above channel bed (and below water level). The flap is an actuator with $4.15 \mathrm{~m}$ height and $12.00 \mathrm{~m}$ width, articulated $2.30 \mathrm{~m}$ above channel bed, as it shown in Fig. 2 .

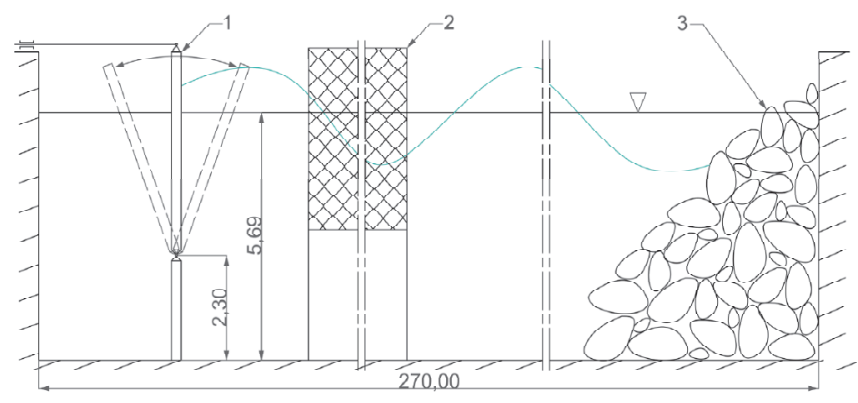

Fig. 2. Longitudinal profile of deepwater towing tank with the wavemaker (1), waveguides (2) and artificial beach (3) (dimensions are given in meters).

\section{SURVEY OF RELATED WORKS}

In 1951, F. Biésel and F. Suquet published formulas known as Biésel Transfer Functions BTF. The BTF allow to calculate the wave height in a towing tank for several types of wavemakers, also for wavemaker with rigid flap and single articulation above channel bed, like in CTO S.A. [1].

The research carried out in 1972, in the Laboratório Nacional de Engenharia Civil (Lisbon, Portugal) has shown that $B T F$ is proper for regular waves. However, for irregular waves, the measured transfer function is inconsistent with theoretical BTF. [2] One possible reason indicated by the authors was the lack of linearity and energy losses.

In 1985, S. Hasselmann and K. Hasselmann described a mechanism of the formation of the JONSWAP spectrum and proposed a model of the nonlinear energy transfer in wind waves [3]. The model has two parameters proposed by the authors. Proper parameterization of the model allows to calculate an energy stream transferred from higher frequency bands to lower frequency bands of the wind wave spectrum.

Van Vledder in 2012 discussed the ambiguity of selection of values of the $C$ and $\lambda$ parameters [4].
In 2014 group of people from Kyushu University (Japan), carried out simulations and study for the method mentioned and for a few others methods of wave model implementation [5].

The control system of the wavemaker in the CTO S.A. deepwater towing tank was modernized in 2015 - an analog control system was replaced by a new digital control system [6]. In 2017 research was conducted on optimization of the digital control system [7].

Research described in this paper is intended to develop mentioned works to enable the prediction of wave characteristics in CTO S.A. deepwater towing tank.

\section{OBJECTIVES AND SCOPE OF THE WORK}

The objectives of research were to determine the way of wave propagation and to develop the method of prediction of the wave characteristics in the CTO S.A. deepwater towing tank. For this purpose, transfer function for the wavemaker and further the impact of the damping, breakdown and reflection were investigated. The scope of research included the measurements of the waves along whole measurement area and analysis of registered signals.

\section{SOLUTION}

\section{MEASUREMENTS}

The measurements were made along whole measurement area of the towing tank, between $1^{\text {st }}$ end on the beach side and $2^{\text {nd }}$ end on the wavemaker side. The $1^{\text {st }}$ end is in $205 \mathrm{~m}$ distance from thewavemaker. The $2^{\text {nd }}$ endisin 60 mdistancefrom thewavemaker. The measurements were made during generation of the waves: regular and irregular. The regular wave is a harmonic wave. The irregular wave is a synthesis of harmonic waves corresponding to the determined spectrum. Parameters of the generated and measured waves are shown in Tab. 1 .

The waves were measured by the resistance probe of the water level (Fig. 3), manufactured by CTO S.A. The resistance probe was mounted to the towing carriage in the towing tank axis, i.e. on the actual track of the models tested in waves. During wave generation, the displacement of the wavemaker flap was measured by linear displacement sensor WDS-1000-P60-SR-U manufactured by MicroEpsilon. 
Table 1. Parameters of the generated and measured waves

\begin{tabular}{|c|c|c|c|}
\hline No. & Type of the wave & $\begin{array}{l}\text { Height of the } \\
\text { wave HW }[\mathrm{cm}]\end{array}$ & $\begin{array}{l}\text { Frequency of } \\
\text { the wave } \mathrm{f}[\mathrm{Hz}]\end{array}$ \\
\hline 1 & regular & 2.5 & 0.8 \\
\hline 2 & regular & 2.5 & 0.9 \\
\hline 3 & regular & 2.5 & 1.0 \\
\hline 4 & regular & 2.5 & 1.1 \\
\hline 5 & regular & 2.5 & 1.2 \\
\hline 6 & regular & 5.0 & 0.3 \\
\hline 7 & regular & 5.0 & 0.4 \\
\hline 8 & regular & 5.0 & 0.5 \\
\hline 9 & regular & 5.0 & 0.6 \\
\hline 10 & regular & 5.0 & 0.7 \\
\hline 11 & regular & 5.0 & 0.8 \\
\hline 12 & regular & 5.0 & 0.9 \\
\hline 13 & regular & 5.0 & 1.0 \\
\hline 14 & regular & 5.0 & 1.1 \\
\hline 15 & regular & 5.0 & 1.2 \\
\hline 16 & regular & 10.0 & 0.3 \\
\hline 17 & regular & 10.0 & 0.4 \\
\hline 18 & regular & 10.0 & 0.5 \\
\hline 19 & regular & 10.0 & 0.6 \\
\hline 20 & regular & 10.0 & 0.7 \\
\hline 21 & regular & 10.0 & 0.8 \\
\hline 22 & regular & 10.0 & 0.9 \\
\hline 23 & regular & 10.0 & 1.0 \\
\hline 24 & regular & 10.0 & 1.1 \\
\hline 25 & regular & 10.0 & 1.2 \\
\hline 26 & irregular & $H_{1 / 3}{ }^{(*}=9.5$ & $f_{01}{ }^{(* *}=0.75$ \\
\hline 27 & irregular & $H_{1 / 3}{ }^{*}=12.9$ & $f_{01}{ }^{(* *}=0.78$ \\
\hline 28 & irregular & $H_{1 / 3}{ }^{*}=14.1$ & $f_{01}^{(* *}=0.69$ \\
\hline
\end{tabular}

${ }^{*}$ significant height of the irregular wave

(** average frequency of the irregular wave (corresponding to average period of the irregular wave T01)

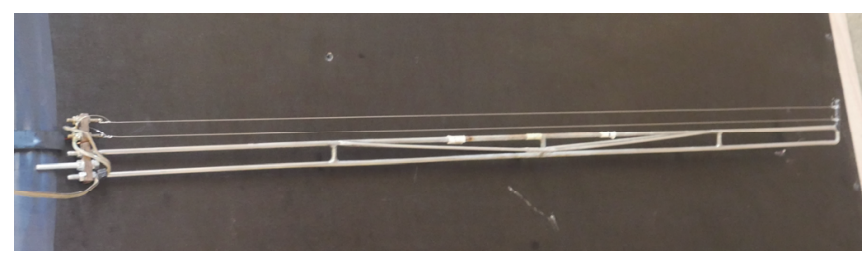

Fig. 3. Resistance probe of the water level manufactured by CTO S.A.

\section{TRANSFER FUNCTION}

For rigid flap wavemaker with single articulation above channel bed, the wave height $H W$ is dependent on flap displacement $a$, wave frequency $f$, water depth $h$ and articulation height above channel bed $h 0$ [1]. The formulas representing this dependence are given as (1) and (2). The Biésel Transfer Function BTF is understood as the relation (3). The $B T F$ for mentioned type wavemaker was experimentally checked for two types of waves - regular and irregular, in the scope consistent with Tab. 1. For this purpose, two signals were measured: the wave $H W-$ measured at the 2nd end of the measurement area using resistance probe and the flap displacement $a$ - measured using the displacement sensor.

$$
\begin{gathered}
H W=\frac{2 \cdot a}{k \cdot(h-h 0)} \cdot\left[\frac{\sinh (k h) \cdot((h-h 0) \cdot k \cdot \sinh (k h)-\cosh (k h)+\cosh (k h 0))}{\sinh (k h) \cdot \cosh (k h)+k h}\right] \\
k=\frac{2 \pi \cdot f^{2}}{1.56} \\
B T F=\frac{H W}{a}
\end{gathered}
$$

\section{Regular waves}

The BTF for regular waves in the CTO S.A. deepwater towing tank with the rigid flap wavemaker was checked. The theoretical BTF was corrected as it shown in (4). Implementation of the correction factor $C r=0.8$ was necessary to obtain the agreement of the calculations with the results of measurements. As shown in Fig. 4, the results of the measurements are consistent with the calculated BTFcorr with satisfactory accuracy.

$$
\text { BTFcorr }=C r \cdot B T F
$$

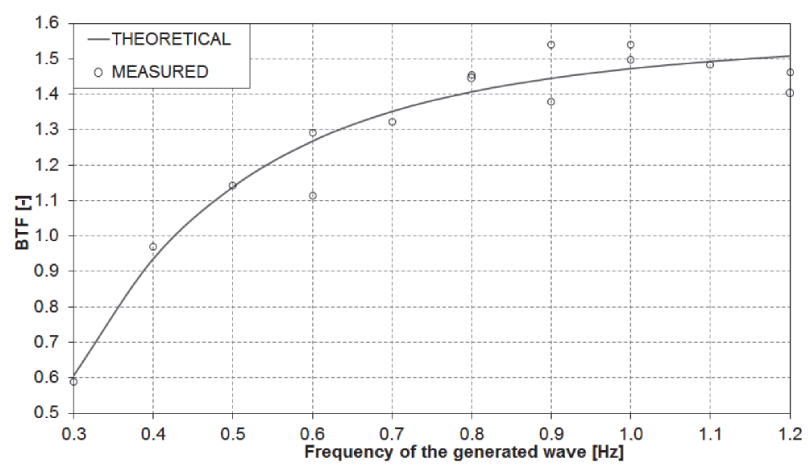

Fig. 4. The transfer function for the regular waves in CTO S.A. deepwater towing tank

\section{Irregular waves}

The transfer function for irregular waves $T F$ was obtained, based on the FFT analysis of the signal $H W$ and signal $a$. The signals were measured for irregular waves no. 26-28 (Tab. 1). As it shown in Fig. 5, the measured TF is consistent with the calculated BTFcorr in scope from $0.3 \mathrm{~Hz}$ to $0.6 \mathrm{~Hz}$. For frequencies higher than $0.6-0.7 \mathrm{~Hz}, T F$ is significantly increasing and further rapidly falling below BTFcorr characteristic.

The rapidly falling characteristics below the theoretical transfer function has been also observed in other hydrodynamics laboratory [2]. It is mentioned there that this phenomenon may be due to lack of linearity and probably 
caused by energy losses as effect of the variations of velocity and acceleration in irregular waves.

Other works devoted to gravity waves, like [3] and further [4] and [5], describes and proves that in the wind waves there are nonlinear interactions that cause the nonlinear energy transfer. It occurs in this way that the energy stream $S n l$ is transferred from higher frequency bands to lower frequency bands of the wind wave spectrum. A similar phenomenon can occur in irregular waves generated in the towing tank. It can be seen in Fig. 5 .

These papers ([3], [4], [5]) describe the physics of the phenomenon and the methods of calculation $S n l$ for wind waves spectra.

The mathematical model of nonlinear energy transfer proposed in [3] is described by formula (5), where: $\delta S n l$ relates to the frequency $\mathrm{f}, \delta \mathrm{Snl}^{+}$relates to the frequency (6) and $\delta S n l^{-}$relates to the frequency (7). Furthermore, $C$ is the strength of the nonlinear interaction parameter [3] and $\lambda$ is the Hasselmann's shape parameter [8].

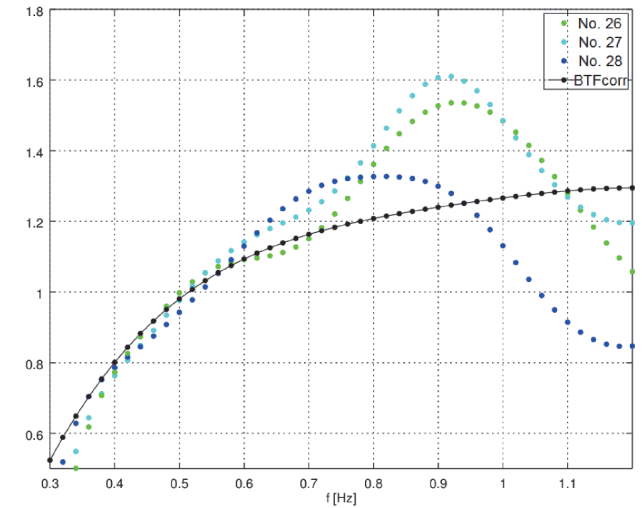

Fig. 5. The transfer functions for the irregular waves no. 26-28

$S n l=\sum_{f=0,1 H z}^{f=1,5 H z}\left[\begin{array}{c}\delta S n l \\ \delta S n l^{+} \\ \delta S n l^{-}\end{array}\right]=\left[\begin{array}{c}-2 \\ 1+\lambda \\ 1-\lambda\end{array}\right] \times C \cdot g^{-4} \cdot f^{11} \cdot\left[F^{2} \cdot\left(\frac{F_{+}}{(1+\lambda)^{4}}+\frac{F_{-}}{(1-\lambda)^{4}}\right)-2 \cdot \frac{F \cdot F_{+} \cdot F_{-}}{\left(1-\lambda^{2}\right)^{4}}\right]$

(5)

$$
\begin{aligned}
& f^{+}=f \cdot(1+\lambda) \\
& f^{-}=f \cdot(1-\lambda)
\end{aligned}
$$

Values of mentioned parameters were proposed as $\lambda=0.25$ and $C=3 \times 106$. The values have been chosen empirically as optimal. Another proposition was given as $\lambda=0.15$ and $C=3.75 \times 105$ [4].

The ambiguity of selecting the parameters may indicate necessity of individual optimization for given towing tank or even for given spectrum.

Following this path, the $\lambda$ and $C$ were chosen individually for each spectrum of the waves no. 26-28 (Tab.1), using binary search algorithm to obtain the best compatibility of the nonlinear transfer function NTF (8) with the measured TF. Chosen parameters are listed in Tab. 2. The results are shown in Fig. 6-8. The $\operatorname{tnl}(9)$ is the time of nonlinear transfer of $S n l$ at the distance $x n l=60 \mathrm{~m}$ between wavemaker flap and resistance probe.

As can be seen in Fig. 6-8 the results of the calculated $N T F$ are consistent with the measured TF with satisfactory accuracy in the frequency scope up to $1.0 \mathrm{~Hz}$.

$$
\begin{gathered}
N T F(f)=\frac{B T F \operatorname{corr}(f) \cdot a(f)+\operatorname{Snl}(f) \cdot \operatorname{tnl}(f)}{a} \\
\operatorname{tnl}(f)=\frac{x n l \cdot f}{1.56}
\end{gathered}
$$

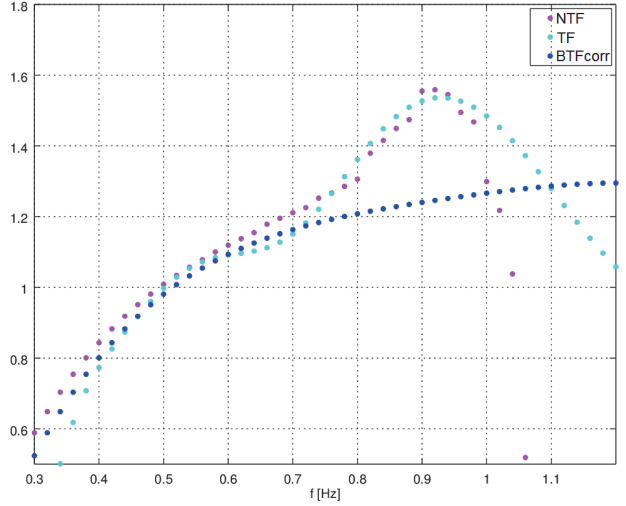

Fig. 6. The NTF for the irregular wave no. 26.

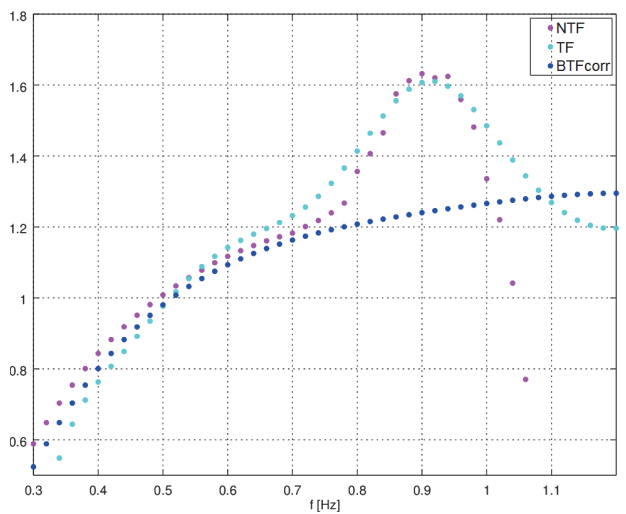

Fig. 7. The NTF for the irregular wave no. 27. 


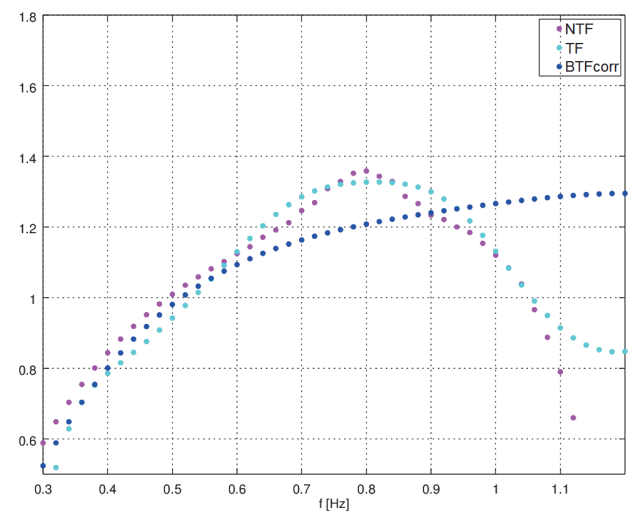

Fig. 8. The NTF for the irregular wave no. 28.

Table 2. Parameters of the nonlinear energy transfer model, chosen for the irregular waves.

\begin{tabular}{|c|c|c|}
\hline No. & Strength parameter C & Shape parameter $\lambda$ \\
\hline 26 & $1.4 \times 107$ & 0.20 \\
27 & $2.4 \times 106$ & 0.22 \\
28 & $1.5 \times 105$ & 0.33 \\
\hline
\end{tabular}

\section{WAVE DAMPING}

The wave damping was investigated on the axis of the towing tank along the whole measurement area. For this purpose, the $H W$ for waves no. 6-15(Tab. 1) was measured at the $2^{\text {nd }}$ end $\left(H W 2^{\text {nd }}\right.$ in Tab. 3) and then at the 1 st end (HW1 ${ }^{\text {st }}$ in Tab. 3). The measurements were made while the towing carriage was stationary.

Relative damping factor $D F$, understood as (10) allows to calculate the $D F$ as function $D F(x)$, where $x=145 \mathrm{~m}$ is the distance traveled by generated wave from $2^{\text {nd }}$ end to $1^{\text {st }}$ end. Dependence of DF on f, shown in Fig. 9, was linearly approximated (11). Finally, the resulting height of the wave under damping conditions as function $H W_{D F}\left(H W 2^{\text {nd }}, f, x\right)$ can be calculated as (12).

$$
\begin{gathered}
D F=\frac{H W 2^{n d}-H W 1^{s t}}{H W 2^{\text {nd }} \cdot x} \\
D F(f)=0.0079 \cdot f-0.0029
\end{gathered}
$$

$$
H W_{D F}\left(H W 2^{n d}, f, x\right)=H W 2^{n d} \cdot[1-(0.0079 \cdot f-0.0029)]
$$

Table 3. Relative damping factors for regular waves, based on wave height on the both ends of the measurement area.

\begin{tabular}{|c|c|c|c|}
\hline $\begin{array}{c}\text { Frequency f } \\
{[\mathrm{Hz}]}\end{array}$ & $\begin{array}{c}\text { Wave height } \\
\text { at the } 2^{\text {nd }} \text { end } \\
\mathrm{HW} 2^{\text {nd }}[\mathrm{cm}]\end{array}$ & $\begin{array}{c}\text { Wave height } \\
\text { at the } 1^{\text {st }} \text { end } \\
\mathrm{HW}^{\text {st }}[\mathrm{cm}]\end{array}$ & $\begin{array}{c}\text { Relative } \\
\text { damping factor } \\
\mathrm{DF}\left[\mathrm{m}^{-1}\right]\end{array}$ \\
\hline 0.4 & 4.88 & 4.72 & 0.0002 \\
0.5 & 4.30 & 4.02 & 0.0005 \\
0.7 & 6.18 & 4.60 & 0.0017 \\
0.9 & 5.62 & 2.72 & 0.0035 \\
1.0 & 5.04 & 0.78 & 0.0057 \\
1.1 & 4.82 & 0.20 & 0.0065 \\
1.2 & 3.68 & 0.12 & 0.0065 \\
\hline
\end{tabular}

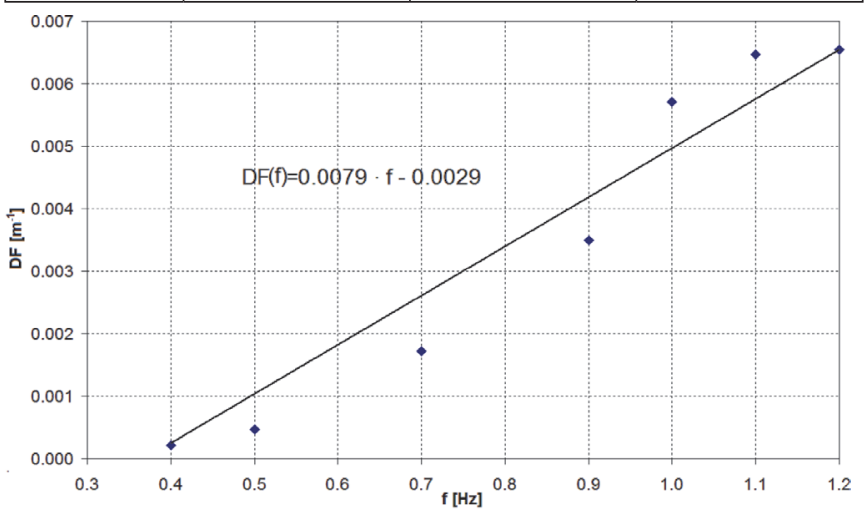

Fig. 9. The damping factor DF as a function of regular wave frequency $f$.

\section{WAVE BREAKDOWN}

The wave breakdown was investigated on the axis of the towing tank between $1^{\text {st }}$ end and $2^{\text {nd }}$ end of the measurement area. The goal of investigation was to determine the content of the power spectral density of harmonic wave at main frequency in the generated waves along whole measurement area. By the main frequency, we mean the frequency generated by the wavemaker. The $H W$ was measured on five sections between $1^{\text {st }}$ end and $2^{\text {nd }}$ end during generation of the regular waves listed in Tab. 1. Each section had length $d x=29 \mathrm{~m}$. Based on the spectrum in frequency domain, obtained from measured $H W$ using FFT, the percentage content of the power spectral density of harmonic wave at main frequency $-P_{\%}$ in the spectrum was calculated according to (13). The $H W_{M}(f)$ means power spectral density of the main frequency band. The $H W_{0.0-1.5 \mathrm{~Hz}}(f)$ means power spectral density of the frequency bands up to $1.5 \mathrm{~Hz}$. Characteristics of $P_{\%}$ as function of $x$ are shown in Fig. 10. As shown, there are a three groups of regular waves due to the dynamics of $\mathbf{P}_{\%}$ changes:

- group A: the waves with frequencies from $0.3 \mathrm{~Hz}$ to $0.9 \mathrm{~Hz}$ - approximated CP1A as (14),

- group B: the waves with frequencies from $1.0 \mathrm{~Hz}$ to $1.1 \mathrm{~Hz}$ - approximated CP1B as (15),

- group C: the waves with frequencies from $1.1 \mathrm{~Hz}$ to $1.2 \mathrm{~Hz}$ - approximated CP1C as (16).

As shown in Fig. 10, the $\mathrm{P}_{\%}$ for waves from the A group is relatively constant. For waves from $\mathrm{B}$ group, the $\mathrm{P}_{\%}$ 
decreases according to S-characteristic and in midway of the measuring area falls below 50\%. For waves from $\mathrm{C}$ group, the $\mathrm{P} \%$ decreases according to J-characteristic and in midway of the measuring area falls to about $20 \%$.

$$
\begin{aligned}
P_{\%} & =\frac{H W_{M}(f)}{H W_{0.0-1.5 H z}(f)} \cdot 100 \% \\
C P 1 A & =0.0095 \cdot x+81.629
\end{aligned}
$$

$\mathrm{CP} 1 \mathrm{~B}=-5 \cdot 10^{-5} \cdot \mathrm{x}^{3}+0.0104 \cdot \mathrm{x}^{2}-0.1872 \cdot \mathrm{x}+21.424$

$\mathrm{CP} 1 \mathrm{C}=-5 \cdot 10^{-5} \cdot \mathrm{x}^{3}-0.0059 \cdot \mathrm{x}^{2}+0.2065 \cdot \mathrm{x}+15.153$

\section{WAVE REFLECTION}

The wave reflection was investigated on the axis of the towing tank between $1^{\text {st }}$ end and $2^{\text {nd }}$ end of the measurement area. The goal of investigation was to determine the reflections arising from the wave reflections from the artificial beach (Fig. 1.) For this purpose, two signals were measured: $H W$ and velocity of the driving towing carriage $V$. The towing carriage was driven from the beach to the wavemaker.

The Doppler effect for measured waves, when towing carriage was driven, allows to extract the mean height of the generated waves $H W g$ and the mean height of the reflected waves $H W r$ from the wave spectrum in frequency domain.
The frequency bands were appropriately shifted depending on measured $V$.

The mean reflection coefficient $\mathrm{R}$, understood as (17), calculated for measured $H W g$ and $\mathrm{HWr}$, is listed in Tab. 4. The numbers in the first column of Tab. 4 are consistent with Tab. 1.

Characteristic of $R$ as function of $\mathrm{f}$ is shown in Fig. 11. As shown, $\mathrm{R}$ ranges from below $10 \%$ up to $25 \%$, depending on the $f$. This dependency was approximated as (18).

Table 4. Reflection coefficient based on generated and reflected waves.

\begin{tabular}{|c|c|c|c|}
\hline No. & $\begin{array}{c}\text { Height of the } \\
\text { generated wave } \\
H W g[\mathrm{~cm}]\end{array}$ & $\begin{array}{c}\text { Height of the } \\
\text { reflected wave } \\
H W r[\mathrm{~cm}]\end{array}$ & $\begin{array}{c}\text { Reflection } \\
\text { coefficient } \\
R[-]\end{array}$ \\
\hline 1 & 3.88 & 0.94 & 0.24 \\
2 & 3.56 & 0.54 & 0.15 \\
3 & 2.72 & 0.58 & 0.21 \\
4 & 2.34 & 0.52 & 0.22 \\
5 & 1.7 & 0.32 & 0.19 \\
8 & 4.44 & 0.4 & 0.09 \\
9 & 4.7 & 0.74 & 0.16 \\
10 & 4.44 & 0.68 & 0.15 \\
11 & 4.76 & 1.18 & 0.25 \\
12 & 4.36 & 0.66 & 0.15 \\
13 & 3.16 & 0.64 & 0.20 \\
14 & 2.12 & 0.54 & 0.25 \\
18 & 8.82 & 0.66 & 0.07 \\
19 & 9.4 & 1.32 & 0.14 \\
20 & 9.26 & 0.88 & 0.09 \\
21 & 7.64 & 1.08 & 0.14 \\
22 & 4.02 & 0.92 & 0.23 \\
\hline
\end{tabular}

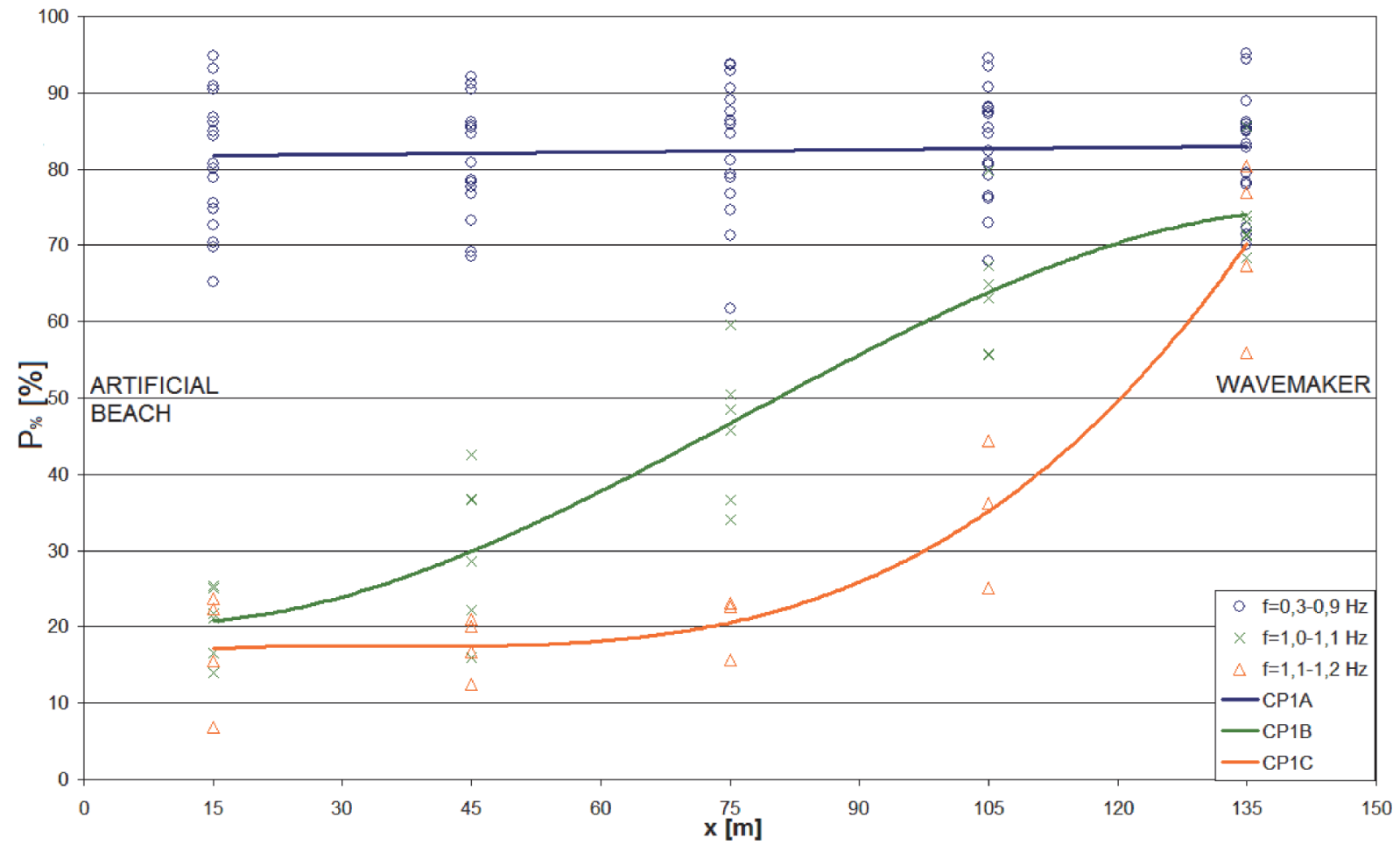

Fig. 10. The content of the main frequency $P \%$ as function of distance $x$. 


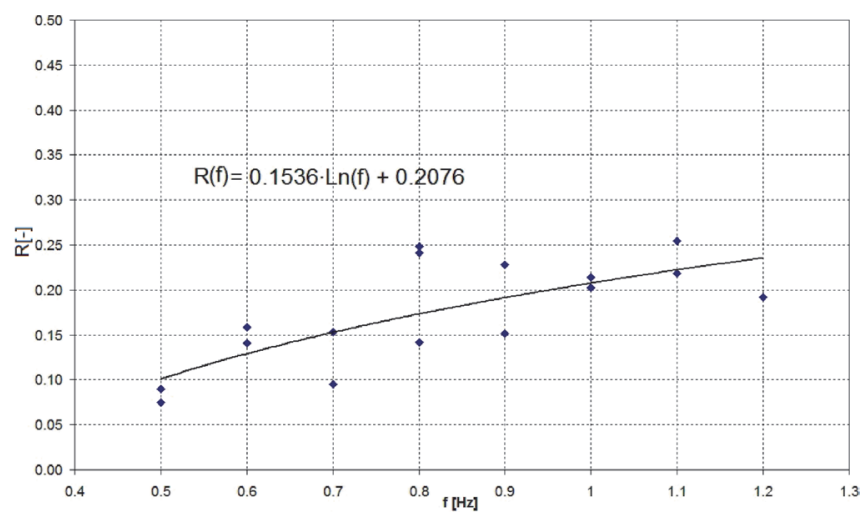

Fig. 11. The reflection coefficient for regular waves $R$ as function of frequency $f$.

$$
\begin{gathered}
R=\frac{H W r}{H W g} \\
R(f)=0.1536 \cdot \ln (f)+0.2076
\end{gathered}
$$

\section{CONCLUSIONS}

In the range of waves listed in Tab. 1, it is valid to use $B T F$ for prediction of $H W$ of regular waves in CTO S.A. towing tank. Moreover, it is possible to use BTF and properly parameterized $S n l$ model for prediction $H W$ of irregular waves.

The wave damping phenomenon is dependent on the $f$. As $f$ increases, $D F$ will increases. It is possible to predict $H W$ on given $x$ and for given $f$ basing on the $H W 2^{\text {nd }}$.

The wave breakdown phenomenon is dependent on the $f$. $P_{\%}$ is constant along the whole measurement area for $f$ up to $0.9 \mathrm{~Hz}$. From $f$ equal to $1.0 \mathrm{~Hz}$ the phenomenon is noticeable and for $f$ above $1.1 \mathrm{~Hz}$ the phenomenon is significant and waves are rapidly collapsing.

The wave reflection phenomenon arising from reflections from the artificial beach is dependent on $f$. As $f$ increases from $0.5 \mathrm{~Hz}$ to $1.2 \mathrm{~Hz}, R$ increases from about $10 \%$ to $25 \%$.

Using the developed modelsof the phenomena: wavedamping, wave breakdown, wave reflection, nonlinear energy transfer and the transfer function, it will possible to predict how the wave will propagate along the measurement area in the CTO S.A. towing tank, basing on wavemaker flap motion control.

Finally, hitherto the wavemaker control system will be developed in CTO S.A. to the adaptive wave control system.

\section{REFERENCES}

1. F. Biésel and F. Suquet, "Les appareiIs générateurs de houle en laboratoire”, La Houille Blanche, no. 2, pp. 161-163, 1951.

2. C. Campos, F. Silveira and M. Mendes, "WAVES INDUCED BY NON-PERMANENT PADDLE MOVEMENTS”, Coastal Engineering Proceedings, vol. 13, pp. 707-722, 1972.
3. S. Hasselmann, K. Hasselmann, J. Allender and T. Barnett, "Computations and Parametrizations of the Nonlinear Energy Transfer in a Gravity-Wave Spectrum. Part II: Parametrizations of the Nonlinear Energy Transfer for Application in Wave Models", JOURNAL OF PHYSICAL OCEANOGRAPHY, vol. 15, 1985.

4. G. van Vledder, "Efficient algorithms for non-linear fourwave interactions", ECMWF Workshop on Ocean Waves, 25-27 June 2012.

5. N. Hashimoto, F. Suciaty, M. Yamashiro, M. Yokota and M. Kodama, "Numerical study on frequency downshift of gravity wave spectra in deep and intermediate water depths due to nonlinear energy transfer", Coastal Engineering, pp. 1-13, 2014.

6. M. Drzewiecki, „Digital Control System of the Wavemaker in the Towing Tank", AUTOMATYKA, ELEKTRYKA, ZAKŁÓCENIA, vol. 7, no. 4, pp. 138-146, 2016.

7. M. Drzewiecki, „Modelling, Simulation and Optimization of the Wavemaker in a Towing Tank", Springer, XIX Polish Control Conference post-conference materials, 2017.

8. The SWAMP group, "Ocean Wave Modeling”, Springer Science+Business Media, p. 225, 1985.

\section{ACKNOWLEDGEMENT}

The research was financed by the Ministry of Science and Higher Education of the Republic of Poland, earmarked for the statutory activity of CTO S.A. Ship Design and Research Centre.

\section{CONTACT WITH THE AUTHOR}

\author{
Marcin Drzewiecki \\ e-mail:marcin.drzewiecki@pg.edu.pl \\ Gdańsk University of Technology \\ 11/12 Narutowicza St. \\ 80 - 233 Gdańsk \\ Poland
}

